
Historic, archived document

Do not assume content reflects current scientific knowledge, policies, or practices. 



\title{
$129 \mathrm{~g}$ \\ [Traducido al español por el Lic. Arturo W. Fergusson.] \\ Circular No. 18, Segunda Serie. (Revisión del No. 14.) \\ Departamento de Agricultura de los Estados Unidos.
}

\author{
DIVISIÓN DE ENTOMOLOGIA.
}

\section{EL PICUDO Ó GORGOJO MEXICANO DE LA CÁPSULA DEL ALGODÓN.}

\author{
(Anthonomus grandis Boh.)
}

\section{ALCANCE DE LA CIRCULAR.}

La circular No. 6 fué publicada en Abril de 1895, y contenía una breve noticia de las observaciones hechas hasta esa fecha, así como las conclusiones basadas en aquellas, respecto del picudo ó gorgojo mexicano de la cápsula del algodón, un insecto de orígen centro-americano que, durante el año de 1894, llamaba en grado considerable la atención en los plantíos de algodón del sud de Texas. La investigación continuó durante el verano, otoño, y los principios del invierno de 1895, hecha principalmente por Mr. Schwarz, que fué á Texas en Mayo y Junio, y otra vez desde Octubre á Diciembre, y por Mr. Townsend, que estuvo estacionado en el Estado durante la mayor parte del verano. El que esto escribe fué á Texas en Diciembre, y en compañía de Mr. Schwarz hizo un estudio detenido del estado de las cosas en esa estación, y habló con muchos cultivadores de algodón notables. Los resultados de estas investigaciones adicionales fueron publicados en la circular No. 14, emitida en inglés y español. Durante el año de 1896 nuevas investigaciones se hicieron por los señores indicados y por Mr. C. L. Marlatt, quien estudió principalmente la cuestión de los remedios, y los resultados que se obtuvieron hacen necesario la publicación de una nueva circular sobre la materia. En ella se han repetido todos los puntos esenciales de las anteriores; la sección sobre remedios se ha escrito enteramente de nuevo, y se ha añadido un párrafo sobre el trabajo del picudo en 1896.

\section{EL ASPECTO GENERAL Y MODO DE TRABAJAR.}

Este insecto es un gorgojo pequeño y parduzco de la forma y aspecto general mostrados en la fig. $1 a$, y mide un poco menos que un cuarto de pulgada de largo. Se encuentra en las labores de algodón durante 
toda la estación, picando y poniendo sus huevos en los papelotes y en las cápsulas. Sus larvas, que son de la forma y aspecto mostradas en la fig. $1 c, \mathrm{y}$ que miden cuando están completamente crecidas un poco más de tres octavos de pulgada de largo, viven dentro de los botones y cápsulas y se alimentan con la sustancia interior. Los papelotes atacados generalmente se caen, pero la mayor parte de las cápsulas dañadas se quedan en la planta, disminuyendo ó achaparrándose, á menos que sea tarde en la estación, en cuyo caso se secan ó pudren.

\section{SU DISTRIBUCIÓN.}

Este insecto por sus destrozos fué causa del abandono del cultivo del algodón en los alrededores de Monclova, en México, por el año de 1862. Hace dos ó tres años que el algodón se sembró de nuevo en esa vecindad, mas el gorgojo se presentó inmediatamente y destruyó la cosecha. En Matamoros hace ocho ó diez años se observó el gorgojo. Por el

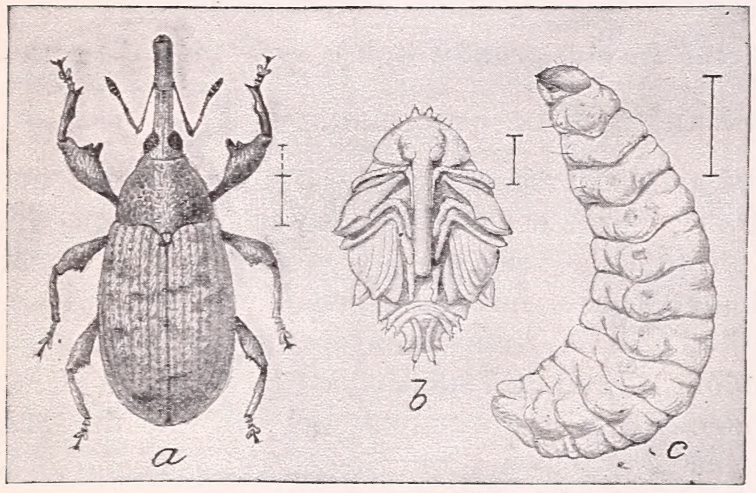

Fig. 1.-El picudo (Anthonomus grandis): $a$, gorgojo adulto; $b$, ninfa ; $c$, larva-en mayor escala.

año 1893 cruzó el río en Brownsville, y en 1894 se le observó en el territorio al rededor de San Diego, Alice, $y$ Beeville. Al fin de la estación de 1894 el insecto ocupaba un territorio que se extendía al norte un poco más allá de Beeville, unas millas al este de este último punto, y al suroeste en las cer-

canías de Realitos, en el Ferrocarril Nacional Mexicano. Los mayores estragos parecen haber sido hechos á lo largo de la parte baja del Rio Nueces. Durante 1895, y particularmente á fines de la estación, extendió considerablemente su campo. Se le encontró hacia el este en mediana abundancia por el valle del Río Guadalupe, en Victoria, Thomaston, y Cuero. Al norte de su antiguo campo se extendió hasta Kenedy, Floresville, y muchos puntos en la región que queda entre este último lugar y Cuero. Cerca de San Antonio se encontró un solo algodonal que contenía gorgojos en número, y de la misma manera se encontró otro lejos al este en Wharton donde los gorgojos habían aparecido tarde en la estación. Las localidades precisas donde se halló el insecto en 1895 están indicadas en el mapa que se acompaña.

TRABAJO DEL GORGOJO EN 1896.

Se temió que en el año de 1896 el gorgojo se extendiese más, pero por alguna razón no explicada, probablemente á causa de la sequía severa del solsticio estival, la extensión no pasó de los límites indicados 
en el mapa de 1895, habiendo habido por el contrario una contracción del territorio infestado. El esparcimiento principal en 1895 se notó en el otoño y en los límites exteriores, pues que en San Antonio y en Wharton el gorgojo fué indudablemente destruido por las heladas del invierno. En un algodonal, por ejemplo, situado cerca de San Antonio, que fué examinado varias veces en $\mathbf{1 8 9 5}$ por Mr. Schwarz, Mr. Townsend, y por el que esto escribe, y en el cual el gorgojo abundó en extremo hasta el mes de Diciembre, no se encontraba ni huella del insecto en 1896. En este año la sequía impidió en muchos puntos la

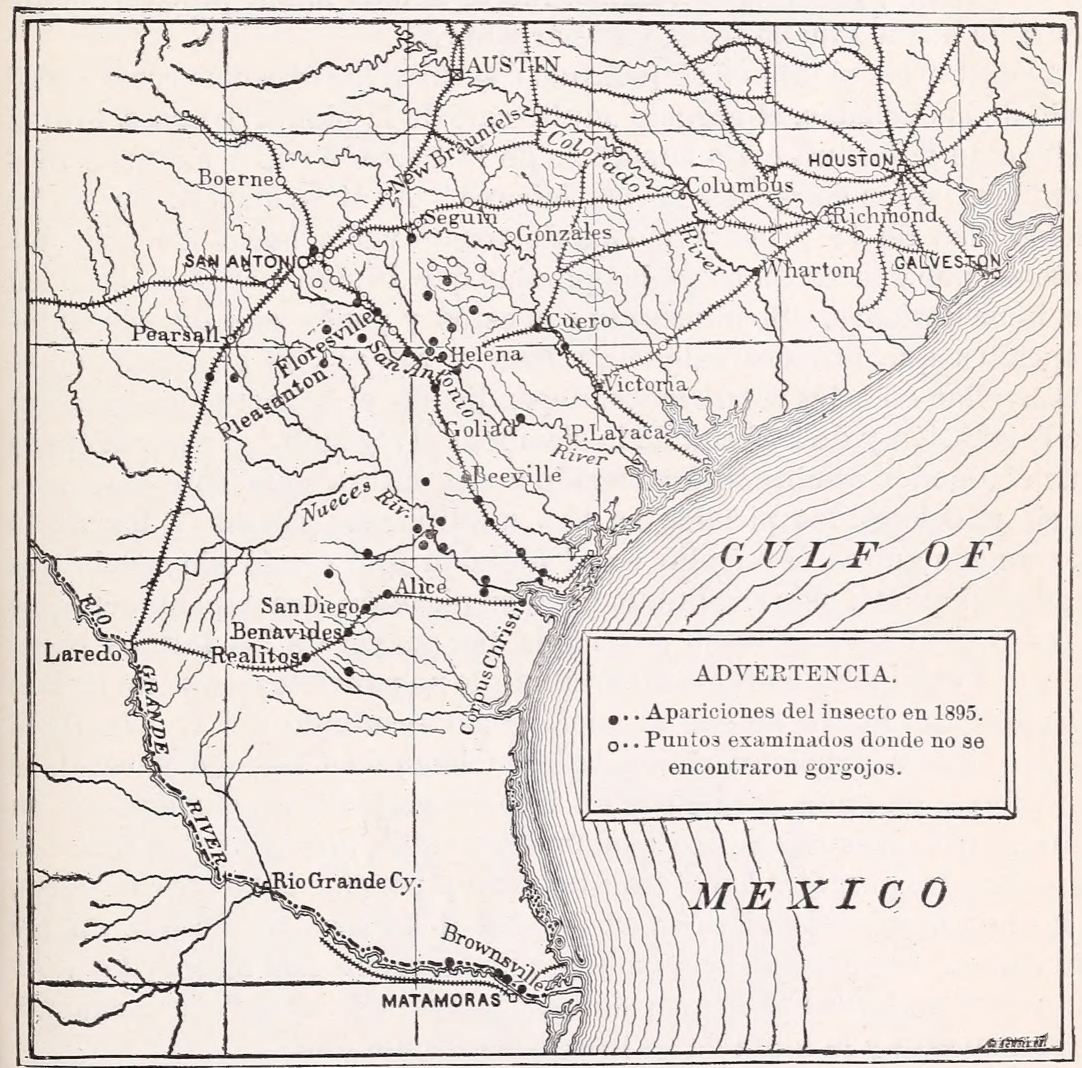

FIG. 2.-Mapa que muestra la distribución geográfica del gorgojo Mexicano de la cápsula del algodón.

formación de la cápsula, y hubo, por consiguiente, poco alimento para el gorgojo en el otoño, y una disminución del esparcimiento desde localidades donde la inveruación fué ventajosa.

\section{SU HISTORIA NATURAL Y COSTUMBRES.}

El invierno lo pasa el insecto en el estado de gorgojo. Se le puede encontrar en la planta del algodón hasta fines de Diciembre, y en efeeto mientras alguna parte de la planta conserve su verdura. Se le encuentra más abundante á principios del invierno escondido entre el envo- 
lucro y la cápsula, y más tarde penetra á las cápsulas secas y abiertas. Todos los ejemplares hallados por Mr. Schwarz en tales condiciones á fines de la primavera de 1895 estaban muertos; mas Mr. Townsend encontró unos cuantos vivos en Marzo. Probablemente la cápsula seca no es con frecuencia buen lugar para invernar. Sin embargo, el juez S. G. Borden, de Sharpsburg, escribiendo con fecha de Enero 27 de 1896, manifiesta que en aquella época se encontraba el gorgojo casi todos los días en las cápsulas secas; pero á este aserto le falta la significación que de otra manera hubiera tenido con respecto á la cuestión de vivir en el invierno, puesto que ninguna fuerte helada había probablemente ocurrido hasta aquella fecha en Sharpsburg.

Al cortar las plantas ó al podrirse ó secarse las cápsulas como resultado de las heladas, el gorgojo adulto sale de la planta y busca abrigo debajo de la basura en la superficie de la tierra, ó entre maleza y desperdicios en las márgenes de las labores. Aquí se quedan hasta los tibios días de la primavera cuando toman vuelo hacia los primeros botones que aparezcan sobre las plantas que brotan por sí mismas en las inmediaciones. Se alimentan con estos y ponen sus huevos en los papelotes que primero salguen, y una, y talvez dos generaciones se desarrollan en tales condiciones, dependiendo el número del caracter de la estación y de la fecha de la siembra del algodón. Ya por la época que el algodón sembrado ha crecido á una altura suficiente para producir papelotes, los picudos se han multiplicado mucho, y los de la generación que se desarrolló en el algodón que creció sin sembrarse atacan el que ha sido sembrado, y por su picadura, sea para alimentarse ó poner sus huevos, causan una caída por mayor de los tiernos papelotes. Parece ser una regla invariable que un papelote en que un picudo ha puesto un huevo se cae al suelo como resultado del trabajo de la larva. En los papelotes caídos la larva llega á su tamaño natural, se transforma en ninfa, y sale por fin insecto perfecto, consumiéndose en esto euatro semanas aproximadamente. Más tarde, al formarse las cápsulas, los gorgojos las atacan también y ponen sus huevos en eilas, y las larvas se desarrollan en su interior del mismo modo que en los papelotes. Las cápsulas sin embargo no se caen. Las figuras 3 a y $3 b$ muestran las larvas en los papelotes, y la figura $3 c$ muestra una cápsula tierna abierta y la ninfa en su puesto acostumbrado.

Hay una sucesión constante de generaciones desde los principios de la primavera hasta las heladas, aumentándose constantemente los gorgojos así también como las larvas y las ninfas. Una sola hembra se ocupará por un número considerable de días poniendo sus huevos, así es que por Julio se nota una confusión intricada de generaciones, y el insecto se puede encontrar en las labores en todos los grados de crecimiento á un mismo tiempo. Las cápsulas, como acabamos de decir, no se caen como lo hacen los papelotes, pero se descoloran gradualmente, en general de un solo lado, y al tiempo que la larva llega a su completo desarrollo generalmente se abren en el extremo. Aunque en 
un papelote no se encuentra generalmente sino una sola larva, en una cápsula completamente desarrollada se hallan las más veces hasta doce. En todos los casos, sin embargo, el engendro de una sola larra resulta en la destrucción de la cápsula hasta el grado de hacer que su fibra se vuelva inútil. Donde no hay serias heladas en Diciembre todos los insectos, ó casi todos, llegan á la madurez y entran en sus cuarteles de invierno, aunque en Sharpsburg se han encontrado larvas hasta en el mes de Enero. Cuando hay una fuerte helada en este mes, ó antes, las observaciones del último otoño demuestran que aquellos insectos que no han llegado al grado de gorgojo estan casi todos muertos. De este hecho se deduce que el insecto probablemente no será tan dañino en otras partes de la región algodonera como lo es en el sud de Texas.

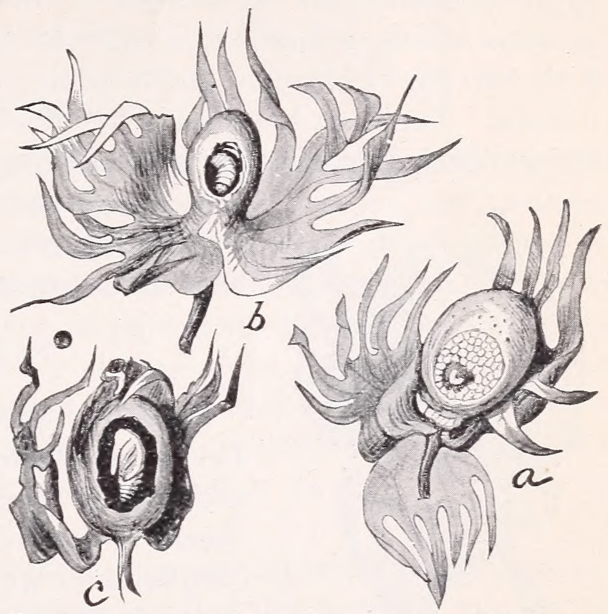

Fig. 3.- $a$, Larva acabada de nacer en papelote tierno; $b$, larva casi completamente desarrollada in situ; $c$, ninfa en cápsula eucontrada en el suelo.

A fines de 1895 se descubrió que el picudo se notaba en muchas localidades donde los cultivadores mismos no lo habían conocido. Es importante que todo cultivador que vive en la región que hemos trazado, ó cerca de ella, pueda descubrir el picudo tan pronto como apa-

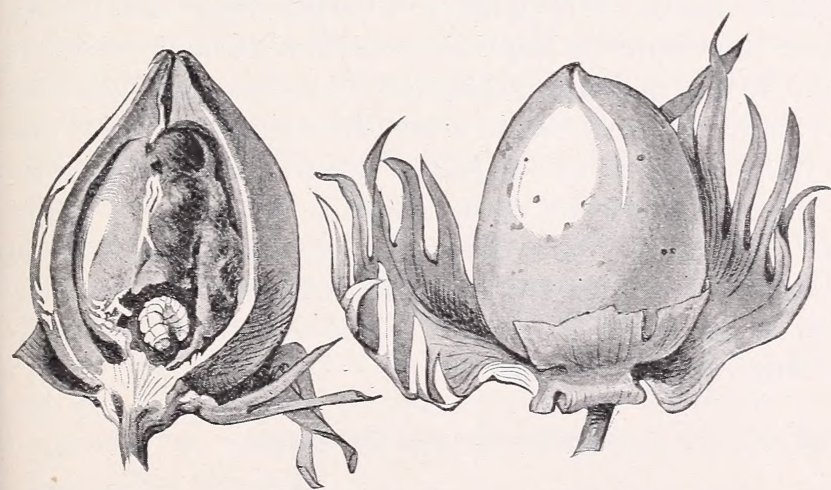

Fig. 4.-El dibujo de la izquierda es un corte de una cápsula madura y mues. tra la larva completamente desarrollada; el que está á la derecha es una cápsula no cortada y muestra agujeros de alimentación y señales de haberse puesto los huevos.

rezca en sus labores. Donde existe una labor mal infestada, una señal de que el insecto está presente es la ausencia de flores. A principios de la estación los picudos atacan á los papelotes primeros $\mathrm{y}$ estos se marchitan y se eaen. Unalabor puede estar toda en flor, y tan pronto como el insecto se extiende bien por ella, escasamente se vé una flor. Sin embargo esta caída sola no es un indicio suficiente de la presencia del picudo. Los papelotes se caen por otras causas, pero si se abre un número suficiente de los 
papelotes caídos se pondrá de manifiesto la causa. Se podrá reconocer prontamente la larva característica del picudo comparándola con los dibujos que publicamos adjuntos.

Como se ha dicho antes, las cápsulas no se caen. Sin embargo, los agujeros hechos por los picudos al alimentarse son comparativamente característicos, y donde una cápsula está descolorada, y ha empezado á abrirse por el extremo, partiéndola se pueden ver sin trabajo la larva ó ninfa. Tarde en la estación los picudos mismos se encontrarán entre el involucro y la cápsula, como demuestra la figura 5, ó en su defecto

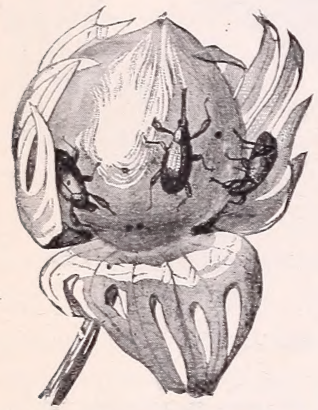

Fig. 5.-Cápsula cojida á fines del otoño mostrando como los gorgojos se esconden entre el cuerpo de aquella y su involucro.

los agujeros de nutrición y el excremento amarillo y granular que se deposita en el involucro en la base de la cápsula son indicios excelentes.

\section{NOMBRES POPULARES.}

Entre los que hablan el español en el sud de Texas, el insecto se conoce generalmente bajo el nombre de "picudo," nombre descriptivo que se refiere á la trompa ó pico del insecto. Los cultivardores que hablan el inglés al principio generalmente se referían al insecto como el "sharpshooter," término que por muchos años se ha dado á cualquier insecto que por sus picadas causa la caída de los papelotes, ó la putrefacción de las cápsulas. Como hay varios insectos del país que comunmente se llaman "sharpshooters," y que, aunque dañinos, de ninguna manera deben compararse con este insecto, se hace necesario de todos modos disuadir que se use la palabra "sharpshooter" al referirse á este gorgojo. Esto se intentó en la primera edición de la circular por medio de un grabado de uno de los más comunes de los insectos llamados "sharpshooters," y llamando la atención á las diferencias radicales que existen entre este y el gorgojo de que se trata. Se recomienda la adopción del término "picudo mexicano de la cápsula del algodón" para esta nueva plaga. El nombre "sharpshooter" se aplica ahora con mucha menos generalidad que al principio al gorgojo. Cultivadores ahora generalmente se refieren á él como el "boll weevil," ó el "Mexican weevil," ó el "Mexican boll weevil."

\section{PARÁSITOS Y ENEMIGOS NATURALES.}

Se puede decir con seguridad que poco es el auxilio que se derivará de los esfuerzos de enemigos naturales y parásitos contra este insecto. De Ios primeros ningunos de importancia han podido observarse. Sin embargo, varios parásitos se han encontrado que lo atacan, y en una ó dos localidades algún bien ha resultado de su trabajo. No han sido abundantes, sin embargo, sino tarde en la estación, después que el gorgojo ha completado su daño anual y en una época en que el bien que se conseguirá con la destrucción de la larva es el mínimo. La 
mayoría de los gorgojos en una labor dada no llega á invernar con éxito, como que el frío ó alguna otra cansa los mata; así es que el trabajo de los parásitos en esta época no cuenta por nada. Cálculos detenidos, sin embargo, muestran que de 15 á 20 por ciento de las larvas de gorgojos en los papelotes caídos en Noviembre en Beeville y Kenedy fueron destruidos por parásitos.

\section{REMEDIOS.}

Al considerar la cuestión de remedios debemos empezar manifestando que la experiencia ha demostrado que ninguna de las aplicaciones generales de sustancias insecticidas será del menor valor contra esta especie como medio de protección de las labores infestadas. En su trabajo en la planta del algodón el gorgojo está enteramente á cubierto de los renenos, puesto que vive y se reproduce en el interior de los botones y papelotes. Sin embargo, como lo demostró la experiencia en la primavera de 1896, los venenos pueden usarse para destruir los gorgojos que escaparon del invierno anterior, y se encuentran eu el algodón que brota por sí mismo.

Al principio de la primavera esos gorgojos escapados del invierno anterior se agrupan en los primeros retoños del algodón viejo y se comen las hojas apenas entreabiertas y los tallos más tiernos; y en este momento se les puede envenenar aplicaudo á esas partes de la planta una preparación arsenical. Para hacer esto será necesario rociar con mucho cuidado los retoños cuando la nueva planta es muy pequeña, y mejor que nunca cuando esta no presenta retoños ó racimos de hojas de más de una ó dos pulgadas de largo. Más tarde no se puede llegar con facilidad á las partes que están brotando. Con una bomba de mochila (knapsack pump) ordinaria puede rociarse una labor con mucha rapidez, y haciendo eficaz el tratamiento indicado; pero es iudispensable dirigir el chorro á los lugares mismos en que aparezcan los retoños. La primera aplicación debe hacerse tan luego como estos empiezen á brotar, y será bueno, talvez repetirla dos ó tres veces, con intermedio de una semaua. En el orden general del cultivo, el número de estas plantas de crecimiento espontáneo es relativamente pequeño, y el tiempo que se necesita para rociarlas cabalmente no será mucho. Debe usarse una solución fuerte, compuesta de 1 libra del veneno para כ0 galones de agua, porque en realidad el daño no será muy grande, aunque las plantas de crecimiento espontaneo se destruyan por la acción del veneno.

La practicabilidad de este método ha sido demostrada, pero existen abundantes pruebas de que el mejor modo de dominar el gorgojo consiste en la adopción del cultivo que más tarde se describirá, y que hace imposible toda clase de crecimiento espontáneo.

El envenenamiento y los demas paliativos que se refieren á crecimientos de esta clase se dan, por tanto, solamente como medio de corregir un mal que puede resultar si el sistema de cultivo referido se ha 
desatendido. Estas observaciones se aplican, por ejemplo, al sistema de trampas que autes hemos recomeudado entre otros. Este consiste en atraer los gorgojos que primero aparezcan á unas pocas plantas algodoneras que se hau dejado en puntos convenientes y protegidas contra los rigores del invierno, y cuyo rápido crecimiento se ha forzado por medios artificiales hasta conseguir que echen ramas y adquiran botones muchas veces antes del algodón espontáneo. Los gorgojos pueden recogerse con la mano con facilidad en los primeros días cálidos, ó pueden, si se quiere, ser muertos por medio del veneno de la manera que antes se indicó.

El hecho de que la generación de la primavera se desarrolla solamente sobre el algodón espontáneo ha sugerido la posibilidad de que el insecto no se esparcirá más allá de la región donde aquel algodón crezca en la primavera, pero desgraciadamente no se puede contar en absoluto con esta posibilidad. Sin embargo, no se puede aconsejar con demasiada energía la destrucción de aquellos retoños voluntarios que aparezcan en los maizales y labores abandonados que en el año anterior se sembraron de algodón, á menos que se envenenen sistemáticamente, porque es materia de observación que la sombra que proporciona el maíz ó yerba rigorosa que crece en las labores abaudonadas es parti. cularmente favorable para el desarrollo de los gorgojos.

Mientras esten tiernas las plantas, y donde el trabajo sea tan barato como en el sud de Texas, mucho bien se puede couseguir recogiendo y quemando los papelotes caídos, y si esto se hace prontamente se destruirá un grau número de los insectos. Debe hacerse á lo menos dos veces, á intervalos de tres semanas, durante la época en que las plantas son pequeñas. Sin embargo, tan luego como las plantas empiezan á echar ramas, este método se hace impracticable por cuanto es difícil encontrar los papelotes en el suelo.

La idea de recoger las cápsulas atacadas durante el tiempo de la cosecha fué sugerida en la primera relación que publicó el que esto escribe. Se pensó entónces que las cápsulas atacadas se podrían reco. nocer tan proutamente que se podrían destruir muchos miles de los insectos por los recogedores del algodón recogiendo estas cápsulas atacadas y llevándolas á otra parte en un receptáculo separado para quemarlas. Sin embargo, el monto del trabajo extraordinaric que euvuelve esta operación sería muy considerable, y las cápsulas atacadas elı muchos casos no suelen reconocerse á una mirada.

Durante el año pasado Mr. Stronball, de Beeville, ha inventado una máquina para sacudir las plantas jóvenes atacadas y recoger los papelotes y cápsulas que caigan por efecto de este sacudimiento. Este aparato ha sido puesto á prueba parcialmente en la estación pasada, pero no se le vió trabajar por ninguno de los entomologistas que estáu haciendo la investigación. Está arreglado de manera que acepilla fuertemente el algodón en ambas direcciones, y las cápsulas y papelotes Hojas se cogen en bandejas para ser después quemadas ó destruídas 
de otra manera. Los cepillos trabajan en direcciones opuestas, y golpean el algodón de los dos lados. Puede ajustarse á plantas de diversas edades.

La investigación detenida de este gorgojo en los íltimos dos ó tres años por la División de Entomología ha demostrado plenamente la importancia suprema del método de dominación que consiste en el cul tivo á euyo hecho dimos prominencia particular en nuestra primera circular sobre este insecto. Ya no puede haber duda que el remedio completo práctico contra el gorgojo existe en el sistema propio de cultivar el algodón. En primer lugar, se ha demostrado sin duda alguna, que las condiciones de cultivo que hacen posible los retor̃os espontá neos hacen también inevitable la continuación del gorgojo. Lo de primera importancia es remover el algodón viejo á principios del otõ̃o, preferiblemente en Noviembre ó antes. Esto puede hacerse completamente arrancando las plantas viejas, raíz y todo, por medio del arado, y después juntándolas y quemándolas. Este tratamiento debe ser seguido, tan pronto como se pueda, por la abertura de surcos profundos como, por ejemplo, de 6 á 8 pulgadas, por medio de un arado. Esto deja el campo comparativamente limpio de tallos viejos, facilita el cultivo esmerado en el año siguiente, y al mismo tiempo, recoge $y$ destruye todas las larvas y ninfas de los picudos y la mayoría de los insectos adultos que allí se encuentren. Los picudos que se escapen se enterrarau al ararse el terreno, y no llegarán otra vez á la superficie. Pocos y talvez ningunos de ellos llegarán á invernar faltándoles la basura ordinaria en los campos en que inviernan. Los campos trabajados de este modo han dado una demostración práctica de la utilidad del método.

El mayor peligro que presenta el gorgojo se debe á la presencia del algodón espontáneo, porque este implica que haya alimento temprano para los gorgojos en la primavera y medios abundantes para que sobrevivan al invierno, y el esfuerzo que se hace para guarlar los retoños voluntarios y conseguir algodón temprano, ó "la primera paca," es una amenaza muy seria al cultivo de algodón dentro del distrito del gorgojo.

Este método de cultivo, si se practicase generalmente, sin duda vendrá á ser un remedio perfecto para el algodón superfino, y reducirá grandemente el daño del gorgojo en las tierras bajas, donde es más probable que el insecto invierue, bien en los bosques vecinos, ó en la vegetación á orillas de los caminos. La pronta remoción del algodón por los medios sugeridos es cosa que se aconseja, particularmente cuando la presencia del gorgojo demuestra que el recogimiento de una cosecha es problemático. En tales circunstancias sería bueno arrancar y destruir los tallos del algodón en Setiembre ú Octubre, como hubiera podido hacerse muy bien con mucho del algodón superfino en 1896. Si este método de cultivo puede hacerse obligatorio, bien por leyes que dicten los Estados, ó por la cooperación é insistencia de parte de los 
hacendados en hacer que sus arrendatarios lo pongan en práctica, no cabe duda que la dificultad del gorgojo puede conquistarse en gran parte.

Además del tratamiento del algodón en el otoño habrá de hallarse de valor considerable el constante y completo cultivo de la planta hasta la época más tarde posible, pues que de esto depende que asegure un buen rendimiento. Con $u n$ cepillo arreglado convenientemente para frotar las plantas, muchos de los botones y papelotes que contienen picudos caerán al suelo donde serán enterrados con los demás que hayan caído por otras causas, y donde por virtud de la liumedad se pudrirán en gran parte, destruyéndose un gran tanto por ciento del material en que se hubieran desarrollado los insectos.

Estará grandemente en el interés de todos los cultivadores de algodón en el distrito prolífico que queda al nordeste de la región ahora infestada apremiar la adopción de una ley durante las sesiones de 1596-97 que provea el remedio para 1897. Esta ley debe prescribir el nombramiento de comisionados en cada condado á solicitud de cierto número de los vecinos. Estos comisionados deben estar autorizados para aplicar el remedio, hacerlo forzoso, imponer penas, y hacer que lo apliquen sus propios agentes, cargando el costo á las haciendas. Sería bueno que esta ley tuviese ámplia esfera de acción, y que no se limitase su aplieación á este insecto particular, sino á todos los otros que son daũinos en el caso de emergencias de semejante naturaleza en el porvenir. Tal ley debía adoptarse en cada uno de los Estados de la Unión. Aunque quedase sin operación por años su aplicación sería útil en el caso de una emergencia súbita, tal como la introducción de un nuevo insecto dañino de un país extrangero, ó la multiplicación y esparcimiento repentino de cualquiera de nuestras especies nativas.

L. O. HoWARD,

Aprobado:

Jefe de la División de Entomología.

Chas. W. Dabney, Jr.,

Subsecretario.

Washington, D. C., Febrero 4 de $189 \%$. 

